very common cause of death after gastric ulcer. Transfusion was to have been done the next day, but unfortunately her sudden death forestalled us.

Tunbridge Wells.

\section{ON PERFORATIONS THROUGH THE ANTERIOR PILLARS OF THE FAUCES.}

By G. G. Morrice, M.D. Cantab., M.R.C.P.

IN The LANCET of Nov. 30th, 1889, Dr. Walter Fowler contributed a Clinical Note entitled "The Significance of Perforations through the Anterior Pillars of the Fauces." He concludes with the sentence, "Hence I look upon these perforations as caused by suppurative or phlegmonous mischief in the tonsils; and, considering the circumstances under which they are generally met with, the lesion is most probably a sign of antecedent scarlet fever." As Dr. Fowler does not mention having actually seen the perforation taking place it may be of interest to record the following cases occurring in diphtheria. They took place in Homerton Fever Hospital. I am indebted to Dr. Collie for leave to publish them.

CASE 1.-N. W—, aged ten. She vomited on Aug. 15th, 1890, and was admitted to the Eastern Fever Hospital next day with membrane on the soft palate to the left of the uvula. - 16th: The greater part of the left side of the palate is covered with thick jelly-like membrane. During the next week the membrane gradually cleared off, but at the same time an oval piece sloughed out of the left anterior pillar, leaving a hole which would admit a cedar pencil. No sign of diminution in its size appeared while she was with us. Summary of the convalescent stage. - 30th: Nasal voice. Sept. 10th : Paralysis of accommodation.-28th : Attacks of vomiting.-29th : Patellar reflex lost. It was excessive, as often happens, for about two weeks before disappearing. Albuminuria, which had appeared on Aug. 8th, disappeared by Sept. 6th.

CASE 2. A. K- aged eight, complained of sore-throat on Feb. 22nd, 1891. On admission to hospital on Feb. 25th there was membrane on the urula, tonsils and soft palate. A watery discharge from the nose.-March 1st: Uvula encased in discoloured membrane.-2nd : Urine contained much albumen (none on admission). -4th: Voice slightly nasal. - 9th: Slough of an oval piece of the left anterior pillar; occasional vomiting; knee-jerks exaggerated.-11th: Drinks return through the nose.-14th : Knee-jerks absent.-30th : Loss of accommodation. April 14th: Strabismus.-15th: Albuminuria ceased; cannot stand alone.-25th: Accommodation regained.-May 5th : No improvement in locomotion.

CASE 3 (from the notes of a colleague).-N. S-, aged two, was admitted to hospital on July 14th, 1891. Bright injection of fauces and soft palate. Yellowish solid-looking deposit on both tonsils. - 18th: Deposit has not yet cleared off. - 22nd: Well-marked purple bloom on the fauces; a small hole through the right anterior pillar where a piece seems to have sloughed through, large enough to admit a bodkin ; no sequelæ.

Now, with regard to scarlet fever, I have recently seen two children with small perforations of the soft palate and a child, who died, in whom most of the soft palate had disappeared. I have also before me the notes of two other cases, one of whom died of pneumonia and nephritis. These I did not see. My observations up to the present time would lead me to think that the most complete and permanent perforations occur in diphtheria. The striking features about them are the similarity of their position (just above the last molar tooth) and the absence of any indication of repair, their edges being as smooth and uniform as those of a gastric ulcer.

Homerton.

\section{CASE OF DISLOCATION OF THE METATARSAL BONE OF THE GREAT TOE.}

By T. Campbeill Grex, M.R.C.S., L.R.C.P. Lond., RESIDENT MEDICAL OFFICER, SWANSEA HOSPITAL.

R. R-, aged twenty-two, engineer, was bronght to the Swansea Hospital on June 13th with a recent injury to his right foot. The accident happened in the following manner. The patient's right foot was on the step of an engine, the posterior part being supported by the step, but the anterior part projecting beyond it. The crank of the engine in its descent struck the projecting part of the foot on its inner and anterior aspect. On examination the skin was abrased over the inner side of the dorsum; the big toe was fixed, the patient being unable to move it; there was a prominence about an inch in front of the tubercle of the scaphoid on the inner part of the dorsum formed by the anterior articular surface of the internal cuneiform; on the inner border of the sole below and behind this was another prominence produced by the displaced base of the first metatarsal bone; this caused a shortening and depression of the arch of the foot. There were no fractures or displacements of any other bones of the foot. I first attempted to reduce the deformity by traction alone, but failed; then, aided by an assistant who pushed forward with his thumb the base of the displaced bone, I was enabled to replace the bone without any difficulty. The case was treated in the usual way; no sloughing of the skin took place, although there had been considerable bruising and at the end of a fortnight the patient was able to begin to use his foot. The rarity of this displacement, unless accompanied with severe injury to the foot, is sufficient excuse for placing the case on record.

Swansea.

\section{As itlitrot}

\section{H O S P T A L PRACTICE, BRITISH AND FOREIGN.}

Nulla autem est alia pro certo noscendi via, nisi quamplurimas et morborum et dissectionum historias, tum alior um tum proprias collectas habere, et inter se compare.-MoRGAGNI De Sed. et Caus. Morb, lib. iv. Procemium.

\section{LONDON HOSPITAT.}

TWO CASES OF PERINEAL PROSTATECTOMY.

(Under the care of Mr. C. Manselu Mouluin.)

THESE two cases illustrate exceedingly well the advantages. and the risks of perineal prostatectomy. In the first complete retention was caused by a comparatively slight degree of overgrowth; the gland had spread up the neck of the bladder along its posterior and left lateral wall until it formed two projecting nodules which, meeting over the orifice when the muscles were set in action, effectually closed it. All that was needed was the excision of the offending mass and the division of the growth beneath it in the neck. By this the obstruction to the exit was completely remored. and then the wall of the bladder, which had lost all power of contraction from over-distension, began slowly to recover. Fortunately there had been no previous cystitis, so that the failure in expulsion was due to atony alone and not to the infiltration of the muscular coats by the products of chronic inflammation. In such a case there can be no doubt the perineal operation is the most suitable. The supra-pubic would probably have given equally great relief but it is certainly more dangerous; cystotomy and drainage might have succeeded, but where it is practicable it is infinitely preferable to re-establish the natural route, and the remaining alternative, catheterism four times a day-by the patient himself or an attendant-could only have had one result. In the second case the conditions were entirely different. Here the lateral lobes were the offending structures; their upward growth had raised a fold between them behind the vesical orifice, but this was firm and rigid, not valve-like. and, though it might have led to the production of a postprostatic pouch, would not of itself have caused complete retention. The chief difficulty, if not the whole, was due to the way in which the increase in their thickness bad compressed the urethra into a narrow slit, through which it was not easy to force the finger. This-aided no doubt by the stricture in front-had created a degree of resistance which the wall of the bladder, weakened as it was by long-continued chronic inflammation, was unable to overcome. Catheterism had become impracticable. The supra-pubic operation would almost certainly have proved fatal, and would not alone have relieved the stricture. Probably in such a case it would have been better to have been content with simple drainage. The bladder 